\title{
El objeto de protección del nuevo juicio de amparo mexicano*
}

\section{The protection's scope of the new mexican amparo}

SUMARIO

Introducción. I. El objeto de protección del juicio de amparo en el régimen jurídico anterior a las reformas de 2011-2013. II. El proceso de reforma al objeto de protección del nuevo juicio de amparo. III. Los criterios de la Suprema Corte y el nuevo objeto de protección del juicio de amparo: A. La incertidumbre inicial sobre la extensión protectora. B. La recepción del "caso Radilla" por la Suprema Corte y su repercusión en el juicio de amparo. C. La contradicción de tesis 293/2011: una construcción implícita del objeto de protección. D. La contradicción de tesis 21/2011-PL: la reconfiguración del amparo directo en revisión ante la Suprema Corte. Iv. Prospectos y retos.

\section{RESUMEN}

El 3 de abril de 2013 entró en vigor una nueva Ley de Amparo en México. El presente artículo presenta una primera aproximación analítica a la modifica-

* $\quad$ Recibido el 9 de diciembre de 2014, aprobado el 20 de febrero de 2015.

Para citar el artículo: A. HerRera García. El objeto de protección del nuevo juicio de amparo mexicano. Revista Derecho del Estado n. ${ }^{\circ}$ 34, Universidad Externado de Colombia, enero-junio de 2015, pp. 153-181. DOI: 10.18601/01229893.n34.08

** Doctor en Derecho por la Universidad Complutense de Madrid (España). Especialista en Derecho Constitucional por la División de Estudios de Posgrado de la Facultad de Derecho de la Universidad Nacional Autónoma de México (UNAM), y por el Centro de Estudios Políticos y Constitucionales (CEPC-Madrid). Secretario académico de la Revista Iberoamericana de Derecho Procesal Constitucional (Editorial Porrúa), desde su fundación en 2003, y secretario de la presidencia del Instituto Iberoamericano de Derecho Procesal Constitucional. Profesor de la Maestría en Derecho Constitucional y Derechos Humanos, y de la Maestría en Derecho Procesal Constitucional, de la Universidad Panamericana (campus Cd. de México). Ha sido analista de jurisprudencia en el Tribunal Constitucional de España (2007-2009); en México, se ha desempeñado como secretario de estudio y cuenta (letrado) del Tribunal Pleno, de la Primera Sala y de la Segunda Sala de la Suprema Corte de Justicia de la Nación (2010-2013); secretario técnico en la Presidencia en el Consejo de la Judicatura Federal (2013-2014), y asesor de la Presidencia en la Sala Superior del Tribunal Electoral del Poder Judicial de la Federación (2014). Contacto: jalfonso.herrera@gmail.com Twitter: @jAlfonsoHerrera 
ción del objeto de protección del juicio de amparo. Esta reforma consistió en la expansión de ese objeto a los derechos humanos consagrados en tratados internacionales de los que el Estado mexicano es parte. Así, en primer lugar, se ofrece una comparación entre el esquema anterior y el nuevo, en relación con dicho objeto de protección. En segundo lugar, se explican las principales resoluciones de la Suprema Corte de Justicia que han dado contenido jurisprudencial a las reformas constitucionales y legales del nuevo juicio de amparo (2011-2013), y que superan criterios sustentados bajo el sistema anterior. Finalmente, se hace una reflexión conclusiva acerca de los retos de futuro que depara la reconfiguración normativa del objeto de protección del juicio de amparo.

\section{PALABRAS CLAVE}

Juicio de amparo mexicano; protección jurisdiccional de los derechos humanos; Suprema Corte de Justicia de México; tratados internacionales de derechos humanos.

ABSTRACT

On April 3, 2013 came into force a new Law of Amparo in Mexico. This article presents a first analytical approach to the reform of the protection's scope of this constitutional trial. This reform expanded that scope in order to consider human rights enshrined in international treaties to which Mexico is party. In this sense, firstly, a comparison is made between the old and the new scheme of the protection's scope. Secondly, I explore the major decisions of the Supreme Court of Justice that have given content to the new amparo (2011-2013), which have overruled its own interpretations given under the old system. Finally, I offer some concluding remarks about the future challenges in the reconfiguration of the protection's scope of the mexican amparo.

KEYWORDS

Mexican amparo judgement; judicial protection of human rights; Supreme Court of Mexico; international human rights treaties.

INTRODUCCIÓN

Con la entrada en vigor de la nueva Ley de Amparo el 3 de abril de 2013, se hace necesaria una primera aproximación analítica a las instituciones de ese ordenamiento, sobre todo a las que han sido renovadas con profundidad, a efecto de calibrar los retos que esta inédita legislación plantea para la comunidad jurídica de México. 
En este sentido, el propósito de este trabajo es, en primer término, ofrecer una comparación entre el esquema anterior y el nuevo, en relación con el objeto de protección del juicio de amparo. En segundo lugar, se busca ofrecer una descripción de las principales resoluciones que representan la superación de criterios sustentados bajo el sistema anterior y, al mismo tiempo, los primeros pasos hacia adelante en la clarificación del contenido jurisprudencial de las reformas constitucionales y legales del amparo (2011-2013), por parte de la Suprema Corte de Justicia. En tercer lugar, se ofrece una reflexión conclusiva, pero, si se permite la expresión, eminentemente provisional, acerca de los retos de futuro que depara la reconfiguración normativa del objeto de protección del juicio de amparo.

Debe advertirse en estas líneas introductorias que, con miras a objetivos prácticos, el presente trabajo reduce al mínimo los insumos dialógicos con otras fuentes doctrinales, así como con el derecho comparado. Con ello, se pretende ofrecer un ensayo que enmarque una primera reflexión acerca de unas reformas que, sobra mencionarlo, están llamadas a causar un impacto profundo en las instituciones procesales de tutela de los derechos humanos en México.

I. EL OBJETO DE PROTECCIÓN DEL JUICIO DE AMPARO EN EL RÉGIMEN JURÍDICO ANTERIOR A LAS REFORMAS DE 2011-2013

El objeto de protección del nuevo juicio de amparo, tal como resulta de la reforma constitucional de 6 de junio de 2011, y de la nueva Ley de Amparo, de 2 de abril de 2013, resulta distinto del que caracterizó su tradición, en el régimen jurídico anterior. Ello se debe, en esencia, al renovado estatus de los derechos humanos de fuente internacional que esas modificaciones implican, a efecto de sus posibilidades de defensa mediante este juicio.

La traducción normativa de esas transformaciones resulta expresa tanto en la Constitución como en la nueva Ley de Amparo. Por esa razón, no cabe duda que, junto a otras importantes modificaciones, la que incidió en el objeto de protección es un ingrediente central en la evolución de este medio de control de regularidad constitucional.

La redacción del artículo 103 de la Constitución federal, hasta antes de la mencionada reforma, establecía que, mediante el juicio de amparo, se protegían las "garantías individuales" por leyes o actos de autoridad que las violaran (fracción I). Esta disposición no experimentó alteración alguna desde su redacción original en la Constitución de 1917. Más aún, dicho texto tuvo su inspiración en el artículo 101 de la Constitución de 1857, que era prácticamente coincidente en sus términos, lo que muestra una inmovilidad conceptual, a nivel normativo, en este básico elemento del sistema mexicano del amparo ${ }^{1}$.

1 Esta circunstancia histórica se destaca en la exposición de motivos de la iniciativa con proyecto de decreto que reforma los artículos 94, 100, 103, 107 y 112 de la Constitución 
Como es conocido, la comprensión histórica del objeto de protección del juicio de amparo, en realidad, vivió un momento clave de su desarrollo ya en el siglo XIX, cuando la Suprema Corte admitió su procedencia contra las sentencias judiciales, motivada por la incorrecta aplicación de las leyes, con base en una interpretación en esa dirección del artículo 14 de la Constitución de 1857. Este criterio pervivió con el advenimiento de la Constitución de 1917, aunado a la defensa del principio de legalidad consagrado en su artículo 16. Así, la esfera protectora del amparo, como suele destacarse en la doctrina especializada, abarcó desde los preceptos constitucionales hasta las modestas disposiciones reglamentarias ${ }^{2}$.

El artículo 103 de la Constitución de 1917, en la redacción que sirvió de fundamento al juicio de amparo hasta su reforma en junio de 2011, estableció desde su origen que las controversias de la competencia de los tribunales de la Federación se suscitaban por leyes o actos de autoridad que violaran las "garantías individuales" (fracción I). Esta disposición permaneció vigente, en su redacción formal, durante 94 años.

Como reflejo de lo dispuesto por el artículo 103 constitucional, la Ley de Amparo de 1936 estableció, en su artículo 1. ${ }^{\circ}$ :

Artículo $1^{\circ}$.- El juicio de amparo tiene por objeto resolver toda controversia que se suscite:

I. Por leyes o actos de la autoridad que violen las garantías individuales;

II. Por leyes o actos de la autoridad federal, que vulneren o restrinjan la soberanía de los Estados;

III. Por leyes o actos de las autoridades de éstos, que invadan la esfera de la autoridad federal (cursivas mías).

Política de los Estados Unidos Mexicanos (Iniciativa de senadores, grupo parlamentario del PRI, México, D. F., 19 de marzo de 2009, p. 2, suscrita por los senadores Manlio Fabio Beltrones, Jesús Murillo Karam, Fernando Castro Trenti y Pedro Joaquín Coldwell; que en adelante se citará como "Iniciativa de reforma constitucional"). También se hace en la exposición de motivos de la iniciativa con proyecto de decreto por el que se expide la Ley de Amparo, reglamentaria de los artículos 103 y 107 de la Constitución Política de los Estados Unidos Mexicanos (Iniciativa de senadores, diversos grupos parlamentarios, México, D. F., 15 de febrero de 2011, pp. 2 y 4 , suscrita por los senadores Jesús Murillo Karam y José Alejandro Zapata Perogordo; que en adelante se citará como "Iniciativa de nueva Ley de Amparo-I").

2 Cfr., por todos, Ignacio Burgoa O, El juicio de amparo, 43. a ed., México, Porrúa, 2009, pp. 251-267; Héctor Fix-Zamudio, Ensayos sobre el derecho de amparo, 3. a ed., México, PorrúaUNAM, 2003, pp. 7-16. 
Este texto, en correspondencia con la inmutabilidad de la Constitución en este aspecto, tampoco sufrió modificación alguna hasta su abrogación por el decreto publicado en el Diario Oficial de la Federación el 2 de abril de 2013. Esto significa que la dimensión legal del objeto de protección del juicio de amparo también fue invariable a lo largo de casi 7 décadas y media. Todo lo anterior informa que, tomando en consideración el continuum que se vivió entre la Constitución de 1857 y la de 1917 en este rubro, hasta sus reformas en 2011-2013, las "garantías individuales" fueron un elemento definitorio del juicio de amparo que prevaleció en México durante casi siglo y medio, con todos los extensivos significados-siempre introspectivos desde la perspectiva normativa- que les dio la jurisprudencia de los tribunales de la Federación en esta larga época.

Es imposible obviar otros sentidos en los que, en el ámbito doctrinal, ha podido concebirse el fenómeno "expansivo" del objeto de protección del juicio de amparo. Por ejemplo, Héctor Fix-Zamudio ha establecido que, lejos de caracterizarse como un proceso unitario, el juicio de amparo se transformó en un proceso con distintas facetas, según la función tutelar que adoptara. Así, pudieron distinguirse cinco clases o sectores de amparo: el amparo para tutelar la libertad personal, el amparo contra leyes, el amparo contra sentencias judiciales, el amparo administrativo y el amparo agrario ${ }^{3}$.

No es este el lugar ni el momento para profundizar en las circunstancias históricas de las referidas transformaciones expansivas del amparo, ni de retomar la clasificación doctrinal de los sectores en los que terminó desarrollándose este juicio con el paso de los años. Estas representaciones del objeto de protección ni fueron materia de especial consideración en las aludidas reformas de 2011-2013, ni se relacionan con el específico efecto expansivo que dichas reformas introducen. La orientación expansionista de estas últimas reformas se debe a una ruta distinta, largamente demandada en la doctrina: la consideración de los derechos humanos del orden internacional como objeto tutelar.

Antes de exponer ese trascendental cambio, debe repararse en lo siguiente. No puede pretenderse que los tratados de derechos humanos constituyan un parámetro novedoso de tutela si tomamos en cuenta que estos han sido invocables en las demandas de amparo a través de su vinculación con la alegada violación al principio de legalidad, consagrado en los artículos 14 y 16 constitucionales. No se trata, desde luego, de una novedad en ese sentido. Lo que sí redunda en una evolución normativo-procesal destacable es la previsión expresa de los tratados como fuente de derechos protegibles a 
través de este medio de control, lo cual, además, dista mucho de carecer de importancia práctica.

Circunscribiré la explicación a la reforma de la fracción I del artículo 103, que es la disposición receptora de la mencionada reforma, puesto que sus fracciones II y III no sufrieron cambio destacable alguno ${ }^{4}$, si bien las mismas fracciones de su "artículo reflejo" en la ley sí lo experimentaron, como se destacará más adelante.

\section{EL PROCESO DE REFORMA AL OBJETO DE PROTECCIÓN DEL NUEVO JUICIO DE AMPARO}

La necesidad de un renovado objeto de protección, en un sentido expansivo hacia el orden internacional de los derechos humanos, mantuvo un consenso indiscutido tanto a lo largo del proceso de reforma a los artículos 103 y 107 constitucionales, como en el proceso legislativo que dio lugar a la nueva Ley de Amparo, hoy en vigor.

No puede perderse de vista que, sobre todo el proceso de la reforma constitucional, se enmarcó en un contexto prácticamente paralelo al de la reforma de la Constitución Federal en materia de derechos humanos, publicada 4 días después (10 de junio de 2011). Ambas reformas, en lo que concierne al tema que nos ocupa, se caracterizaron por reconfigurar, conjuntamente, el valor jurídico de los tratados internacionales en materia de derechos humanos en la Constitución Federal mexicana. En este sentido, es imposible entender por separado estas reformas.

Pero el consenso en torno a la necesidad de "expandir" o "extender" el objeto de protección del juicio de amparo tiene raíces más antiguas, cristalizadas en el "Proyecto de nueva Ley de Amparo" elaborado por la Comisión de Análisis de Propuestas para una Nueva Ley de Amparo, designada por el Pleno de la Suprema Corte en noviembre de 1999, que, como se sabe, es un documento en el cual se inspiraron las iniciativas que culminaron con las reformas del 2011-2013, que ahora se analizan. Vale la pena referirse, así sea someramente, a ese importante antecedente.

En la versión final del proyecto elaborado por aquella comisión redactora, que entregó al Pleno de la Suprema Corte en abril de 2001, se llegó a la conclusión de que el juicio de amparo debía incluir la protección de los derechos humanos consagrados específicamente en cinco instrumentos internacionales: la Declaración Universal de los Derechos Humanos, el Pacto Internacional de Derechos Civiles y Políticos, el Pacto Internacional de Derechos Económicos, Sociales y Culturales, la Declaración Americana de los Derechos y Deberes del Hombre y la Convención Americana sobre Derechos Humanos.

4 Estas fracciones solo tuvieron una modificación antes de la reforma de 2011: la que implicó el Decreto del 31 de diciembre de 1994, que, en ambas fracciones, introdujo el supuesto de procedencia del amparo por vulneración o restricción a la soberanía del Distrito Federal. 
Una de las razones por las cuales la comisión consideró pertinente establecer este numerus clausus de instrumentos internacionales como objeto de protección del juicio de amparo, fue la constatación de que existe un buen número de otros instrumentos suscritos por México con gran diversidad temática, muchos de ellos producto de circunstancias políticas coyunturales, que engloban intereses diversos de los distintos Estados, que cuentan con diferentes formas de organización política. Se consideró que esos otros tratados, pactos, declaraciones, etcétera cuentan con fórmulas ambiguas, cuya protección directa mediante el juicio de amparo podría haber provocado consecuencias indeseadas ${ }^{5}$.

Al analizar ese texto, el pleno de la Suprema Corte decidió modificarlo en el sentido extensivo que finalmente trasminó en las iniciativas de reforma constitucional y de nueva Ley de Amparo de 2011-2013. El proyecto de la Corte, de mayo de 2001, propuso que el juicio de amparo debía proteger los derechos contenidos en la totalidad de los instrumentos internacionales de derechos humanos suscritos por México. La finalidad de esa apertura indefinida consistió en permitir la protección de los derechos de fuente internacional de cualquier instrumento, sin necesidad de reformar la Constitución cada vez que alguno de ellos se incorporara al ordenamiento jurídico mexicano.

Pues bien, ha sido esta última propuesta la que, en materia de objeto de protección, hicieron suyas las iniciativas, las cuales, en este aspecto, no tuvieron objeción importante alguna en el seno de los órganos legislativos, tanto durante el proceso de revisión constitucional como en el del proceso parlamentario que culminó con la aprobación de la nueva Ley de Amparo. Así, durante esos procesos, los artículos 103 constitucional y $1 .^{\circ}$ de la Ley de Amparo, que propusieron tales iniciativas, no fueron objeto de debate, si bien hubo una moción para modificar la propuesta de redacción que al último precepto citado dieron las Comisiones Unidas de Justicia, de Gobernación, y de Estudios Legislativos, Segunda, del Senado de la República, como se destacará luego.

En lo que se refiere a la reforma del artículo 103 de la Constitución Federal, vale la pena detenerse en la distinción entre la redacción que contenía la fracción I anterior, y su nuevo texto. Antes de su reforma, esa fracción establecía que los tribunales de la Federación conocerían de toda controversia que se suscitara por leyes o actos de autoridad que violaran las "garantías individuales", en consonancia con lo que la Constitución mexicana expresaba en su título I, capítulo primero, cuya denominación era, precisamente, "De las garantías individuales", y con otros apartes de la propia Constitución que

5 Cfr. Arturo Zaldívar lelo de Larrea, Hacia una nueva ley de Amparo, México, unAm-IIJ, 2002, pp. 28-35; José Ramón Cossío Díaz, “Análisis de la propuesta de una nueva Ley de Amparo”, en íd., Bosquejos constitucionales, México, Porrúa, 2004, pp. 420-432. 
aludían a esa expresión. Tras la reforma del 6 de junio de 2011, el nuevo artículo 103 dispone que los tribunales de la Federación resolverán toda controversia que se suscite:

I.- Por normas generales, actos u omisiones de la autoridad que violen los derechos humanos reconocidos y las garantías otorgadas para su protección por esta Constitución, así como por los tratados internacionales de los que el Estado Mexicano sea parte (cursivas nuestras).

Lo primero que debe destacarse de esta nueva redacción es la distinción que la Constitución introduce entre los "derechos humanos reconocidos" y las "garantías otorgadas para su protección”. Esta distinción explícita es congruente con la que incorpora la diversa reforma de 10 de junio de 2011, en distintos sitios del nuevo texto constitucional, destacadamente en la denominación del capítulo primero del título primero, que pasó a llamarse, justamente, "De

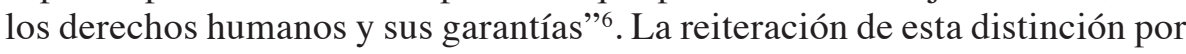
la Constitución enfatiza la imperiosidad de hacer operativo dicho distingo conceptual en la práctica del juicio de amparo.

Vistas en su conjunto, estas modificaciones corrigieron un error histórico de tipo dogmático en el sentido de que, técnicamente, las garantías no podían seguir siendo consideradas, al menos autónomamente, ellas mismas, objeto de protección, sino como vehículos procesales para la defensa de ese objeto, categoría en la que se ubican los derechos humanos. Las garantías son medios de protección, no, en buena técnica, su objeto.

Hay otra modificación en el artículo 103, fracción I, que debe ponerse de relieve: el cambio del lenguaje constitucional en el verbo empleado por el derecho positivo para significar el anclaje de los derechos humanos a la Constitución Federal. Por décadas se estableció que las "garantías individuales" eran "otorgadas" por la Constitución. Con la reforma del 6 de junio de 2011, el artículo 103 ahora dispone que el juicio de amparo protege los derechos humanos "reconocidos" y las garantías "otorgadas" para su protección ${ }^{7}$. Resulta patente la consonancia entre la terminología del capítulo primero, título I, y de los artículos $1 .^{\circ}, 29,33$ (modificados por el Decreto de 10 de junio de 2011), y la del artículo 103, fracción I.

¿Cuál es la consecuencia práctica de lo que se viene de constatar? Para empezar, que en el trabajo cotidiano que implica la elaboración de

6 Acerca de las implicaciones sustantivas derivadas de esta modificación, en apariencia solo nominal, cfr. JoRge CARPIZo, "Los derechos humanos: una propuesta de clasificación de los derechos civiles y políticos", Revista de la Facultad de Derecho de México, t. LXI, n. ${ }^{\circ} 256$, julio-diciembre, 2011, en especial, pp. 32-37.

7 Al respecto, cfr. Sergio García Ramírez y Julieta Morales Sánchez, La reforma constitucional sobre derechos humanos (2009-2011), 2. ${ }^{a}$ ed., México, Porrúa/unam, 2012, pp. 71-78. 
sentencias por todos los tribunales de la Federación, el léxico por ellas utilizado habría de sustituirse: el trabajo judicial debe ahora referirse a los "derechos humanos" tutelables por el juicio de amparo, y ya no a las "garantías individuales", o a su más simple locución tradicional de "garantías". Por otro lado, debe empezar a hacerse patente la utilización de la expresión "garantías" exclusivamente para referirse a todo medio, proceso o procedimiento de defensa, dispuesto por el ordenamiento jurídico, para la protección de esos derechos (entre los cuales se cuenta el propio juicio de amparo). Incluso, a este respecto, la propia iniciativa de la nueva Ley de Amparo presentada por diversos grupos parlamentarios del Senado, de 15 de febrero de 2011, afirma: "es evidente que el juicio de amparo habrá de sufrir una transformación de fondo y no sólo en cuanto a su denominación de "juicio de garantías"”.

Dicho lo anterior, otra cuestión a destacar sobre la reforma del objeto de protección del juicio de amparo, a nivel constitucional, es que ahora se dispone que los derechos y sus garantías deben estar reconocidos y otorgados, respectivamente, por la propia Constitución, "así como por los tratados internacionales de los que el Estado mexicano sea parte". En este punto, se trata de la ampliación propiamente de la esfera de protección del juicio de amparo desde el punto de vista de las fuentes normativas que deben tomarse en cuenta para enjuiciar el acto de autoridad reclamado.

Si bien desde un primer momento ha sido posible observar en las normas positivas la ampliación de dicho objeto de protección a las normas de tratados internacionales, no quedó clara la manera en que debía comprenderse esa "ampliación" o "extensión", sobre todo debido a la "interferencia" que respecto de la tesis de la igual jerarquía de derechos consagrados en tratados internacionales parecían significar la última parte del primer párrafo del artículo $1 .^{\circ}$-si bien reformado por el Decreto de 10 de junio de 2011, intocado en esa parte de su redacción- ${ }^{9}$, y el artículo 133, que no había sufrido modificación alguna con estos decretos ${ }^{10}$.

8 Iniciativa de reforma constitucional, cit., p. 2; Iniciativa de nueva Ley de Amparo-I, cit., p. 5 .

9 "Art. $1^{\circ}$.- En los Estados Unidos Mexicanos todas las personas gozarán de los derechos humanos reconocidos en esta Constitución y en los tratados internacionales de los que el Estado Mexicano sea parte, así como de las garantías para su protección, cuyo ejercicio no podrá restringirse ni suspenderse, salvo en los casos y bajo las condiciones que esta Constitución establece" (cursivas nuestras).

10 De hecho, no ha sufrido reforma alguna desde 1934. Su texto en vigor es el siguiente: "Art. 133.- Esta Constitución, las leyes del Congreso de la Unión que emanen de ella y todos los tratados que estén de acuerdo con la misma, celebrados y que se celebren por el Presidente de la República, con aprobación del Senado, serán la Ley Suprema de toda la Unión. Los jueces de cada Estado se arreglarán a dicha Constitución, leyes y tratados, a pesar de las disposiciones en contrario que pueda haber en las Constituciones o leyes de los Estados". 
Ahora bien, tanto la iniciativa de la reforma constitucional como una de las dos que se presentaron para la nueva Ley de Amparo proporcionaron elementos para orientar el sentido de esa ampliación ${ }^{11}$. En dichas iniciativas se dijo que: a) afines a la lógica internacional, que ha extendido el espectro de protección en materia de derechos humanos, y dada la necesidad de constituir al juicio de amparo en un medio más "eficiente" de control de las actuaciones de las autoridades públicas, se pretende "ampliar el marco de protección de ese proceso extendiendo la materia del control"; y b) deben protegerse de "manera directa", mediante el juicio de amparo, "además de las garantías que prevé la Constitución, los derechos contenidos en los tratados internacionales ratificados por el Estado mexicano" 12 .

Las dos iniciativas de la nueva Ley de Amparo que se presentaron en la Cámara de Senadores, tanto la de diversos grupos parlamentarios ${ }^{13}$ como la del Partido de la Revolución Democrática (PRD) $)^{14}$, coincidían en señalar que debían establecerse expresamente, como objeto de protección del amparo, los tratados de los que el Estado mexicano fuera parte. Sin embargo, discrepaban en su redacción. En lo que aquí interesa, la fracción I del artículo 103, finalmente aprobada, se inspiró más fielmente en el texto propuesto por la segunda iniciativa mencionada.

Como se dijo con anterioridad, la intención inicial del legislador fue introducir en la nueva Ley de Amparo una "disposición espejo" del artículo 103 constitucional. Efectivamente, la iniciativa original de la nueva Ley de Amparo reproducía en sus términos el artículo 103 reformado. Sin embargo, debe llamar la atención que el nuevo artículo $1 .^{\circ}$ de la Ley de Amparo no resulta ser una reproducción exacta de esa disposición constitucional en lo que toca a sus fracciones II y III. Dicho precepto quedó finalmente redactado de la siguiente manera:

11 La iniciativa explora el estado de la cuestión en el derecho comparado al exponer: "Se debe apuntar que en el derecho comparado se ha generado un movimiento diametralmente diferente al que se presencia en México, pues en otros países el ámbito de protección de los juicios constitucionales ha abarcado también lo previsto en materia de derechos humanos por diferentes instrumentos del derecho internacional. Al respecto, las soluciones han variado, pues en algunos casos se ha dado jerarquía constitucional a todos los instrumentos internacionales celebrados por un Estado; en otros sólo a algunos de ellos; en otros se han dejado como objeto de protección, pero sin darle la jerarquía constitucional o en otros, finalmente, se ha previsto que el contenido de esos instrumentos debe guiar la interpretación que de los derechos fundamentales hagan los tribunales nacionales". Cfr. Iniciativa de nueva Ley de Amparo-I, cit., p. 5.

12 Iniciativa de reforma constitucional, cit., p. 2; Iniciativa de nueva Ley de Amparo-I, cit., p. 2.

13 Cfr. supra nota 1.

14 Iniciativa de senador, grupo parlamentario del PRD, México, D. F., 22 de septiembre de 2011, suscrita por el senador Tomás Torres Mercado (en adelante, "Iniciativa de nueva Ley de Amparo-II"). 
Artículo $1^{\circ}$.- El juicio de amparo tiene por objeto resolver toda controversia que se suscite:

I. Por normas generales, actos u omisiones de autoridad que violen los derechos humanos reconocidos y las garantías otorgadas para su protección por la Constitución Política de los Estados Unidos Mexicanos, así como por los tratados internacionales de los que el Estado Mexicano sea parte;

II. Por normas generales, actos u omisiones de la autoridad federal que vulneren o restrinjan la soberanía de los Estados o la esfera de competencias del Distrito Federal, siempre y cuando se violen los derechos humanos reconocidos y las garantías otorgadas para su protección por la Constitución Política de los Estados Unidos Mexicanos; y

III. Por normas generales, actos u omisiones de las autoridades de los Estados o del Distrito Federal, que invadan la esfera de competencia de la autoridad federal, siempre y cuando se violen los derechos humanos reconocidos y las garantías otorgadas por la Constitución Política de los Estados Unidos Mexicanos.

El amparo protege a las personas frente a normas generales, actos $\mathrm{u}$ omisiones por parte de los poderes públicos o de particulares en los casos señalados en la presente Ley (cursivas nuestras).

La alteración de las fracciones II y III del precepto en cuestión se debió al dictamen de las Comisiones Unidas de Justicia, de Gobernación, y de Estudios Legislativos, Segunda, de la Cámara de Senadores, del 5 de octubre de 2011, sin ofrecerse en la exposición de motivos de dicho dictamen explicación específica alguna sobre el particular. Este texto superó todas las etapas legislativas hasta su aprobación definitiva por ambas cámaras legislativas. Al analizarse el contenido de esas fracciones en el pleno de la Cámara de Diputados, en la sesión del 12 de febrero de 2013, esa propuesta de redacción fue objeto de observación por el diputado Manuel Huerta Ladrón de Guevara (Partido del Trabajo), cuando se discutía el dictamen respectivo enviado por el Senado. Sin embargo, esa reserva no fue admitida a discusión ${ }^{15}$.

15 La intervención del diputado LADRÓN DE GUEVARA fue en los siguientes términos: "quise hacer esta reserva porque miren, en el artículo 1 dice: 'El juicio de amparo tiene por objeto resolver toda controversia que se suscite -obviamente, en el párrafo primero-por normas generales, actos u omisiones de autoridad que violen los derechos humanos reconocidos y las garantías otorgadas para su protección por la Constitución Política de los Estados Unidos Mexicanos, así como por los tratados internacionales de los que el Estado mexicano sea parte'.

"Y las fracciones II y III dicen: 'Por normas generales, actos u omisiones de la autoridad federal que vulneren o restrinjan las soberanía de los estados o la esfera de competencia del Distrito Federal -y aquí está el problema porque viene seguido de-siempre y cuando se violen los derechos humanos reconocidos y las garantías otorgadas para su protección por la Consti- 
Sin perjuicio de dejar apuntada la incerteza de cuáles pueden ser las consecuencias prácticas de esa amplificación, incompleta, de los supuestos de procedencia del llamado en la doctrina "amparo-soberanía" en la nueva Ley de Amparo (como se ve, en ambas fracciones se omite aludir a los "tratados internacionales de los que el Estado mexicano sea parte"), lo cierto es que quizá era el momento de prescindir, tanto en el artículo 103 constitucional como en este de la ley, de estos supuestos, considerando que la extralimitación de competencias de la autoridad es susceptible de reclamarse, sin margen de duda, a través de la invocación de la violación al principio de legalidad previsto en el artículo 16 constitucional.

No está de más mencionar que, acordes con el nuevo artículo $1 .{ }^{\circ}$, los artículos 108, fracción VI, y 175, fracción vI, de la Ley de Amparo vigente prevén que en la demanda de amparo (indirecto y directo, respectivamente) han de expresarse, conforme dicho artículo $1 .^{\circ}$, los preceptos que contengan los derechos humanos (y las garantías, en el caso solo del amparo indirecto) cuya violación se reclame. Asimismo, el artículo 107 de la ley enaltece el valor jurídico de los tratados al establecer la inimpugnabilidad de los tratados internacionales en "aquellas disposiciones en que tales tratados reconozcan derechos humanos".

Asimismo, la nueva ley conceptualiza, en la misma dirección, los actos del procedimiento administrativo de "imposible reparación" y los "actos en juicio", a efecto de la procedencia del amparo indirecto. El artículo 107, fracciones III, inciso b), y v, establecen que por tales actos deben entenderse "los que afecten materialmente derechos sustantivos tutelados en la Constitución Política de los Estados Unidos Mexicanos y en los tratados internacionales de los que el Estado Mexicano sea parte".

Por otro lado, el reconocimiento de estos tratados impactó también la operatividad del principio de definitividad del juicio, que ahora se prevé en el artículo 171 de la nueva ley. En el juicio de amparo directo, al reclamarse la sentencia definitiva, laudo o resolución que ponga fin al juicio, no resulta ahora exigible agotar el recurso o medio de defensa previsto por el ordenamiento, entre otros supuestos, en aquellos en los que se "alegue que la ley aplicada

tución Política de los Estados Unidos Mexicanos'. Y en la fracción III: 'Por normas generales, actos u omisiones de las autoridades de los estados o del Distrito Federal que invadan la esfera de la competencia de la autoridad federal -y vuelven a condicionar con un-siempre y cuando se violen los derechos humanos reconocidos y las garantías otorgadas por la Constitución Política de los Estados Unidos Mexicanos'.

"Obviamente, si es técnica legislativa, lo podrán enmendar porque nosotros estamos proponiendo suprimir desde los condicionantes siempre y cuando en ambas fracciones, ya que esto le resta operatividad, funcionalidad, del caso que se acredita. Es obvio en temas presupuestales y demás. No hay violaciones a derechos humanos y éstos ya están protegidos en la fracción I". Cfr. Cámara de Diputados, versión estenográfica de la discusión parlamentaria, México, D. F., 12 de febrero de 2013, p. 18. 
o que se debió aplicar en el acto procesal, es contraria a la Constitución o a los tratados internacionales de los que el Estado Mexicano sea parte".

III. LOS CRITERIOS DE LA SUPREMA CORTE Y EL NUEVO OBJETO

DE PROTECCIÓN DEL JUICIO DE AMPARO

\section{A. La incertidumbre inicial sobre la extensión protectora}

La entrada en vigor del nuevo sistema constitucional del juicio de amparo, primero, y de la nueva Ley de Amparo, después, trajo como consecuencia una consciencia colectiva en el foro jurídico, más o menos general, de que otra, distinta a la tradicional, debía ser la caracterización jurídica del objeto de protección del juicio de amparo. Sin embargo, desde un inicio se plantearon serias dificultades interpretativas acerca de la cabal proyección y los alcances de esa extensión, de cara a la posición normativa del derecho internacional de los derechos humanos.

Para centrar la atención en las discusiones del Tribunal Pleno de la Suprema Corte, debe decirse que la primera resolución que arrojó alguna luz de hacia dónde debía orientarse la comprensión de esa amplificación fue la recaída en el expediente varios 912/2010, si bien fueron más amplias las consecuencias que esta implicó para el entero modelo de control de constitucionalidad en el país. En todo caso, este asunto arrojó las primeras determinaciones del Tribunal Pleno frente a la reforma constitucional de derechos humanos, de imposible desconexión con lo que vendría a regir después para el juicio de amparo, cuya reforma constitucional entró concretamente en vigor el 4 de octubre de 2011, es decir, menos de tres meses después de haberse emitido esa resolución.

El objeto de protección del juicio de amparo encontró otro escalón evolutivo con la resolución a la contradicción de tesis 293/2011, emitida el 3 de septiembre de 2013, y continuó construyéndose con la recaída en la contradicción de tesis 21/2011-PL, decidida el 9 de septiembre siguiente. Puede afirmarse que estas últimas resoluciones marcan sendos puntos de inflexión con respecto a criterios jurisprudenciales típicos del sistema anterior. Sobre todo con la contradicción de tesis 293/2011 han quedado sin efectos jurisprudencias de tribunales de la Federación, y modalizadas otras de la propia Corte, que servían de base para concebir la posición jurídica de los tratados internacionales de derechos humanos, al conocer del juicio de amparo.

\section{B. La recepción del "caso Radilla" por la Suprema Corte y su repercusión en el juicio de amparo}

Pese a que los primeros criterios que se destacarán ahora emanaron de la paradigmática resolución al expediente varios 912/2010, denominado "Caso 
Radilla" (aunque, en propiedad, se trata de la "recepción del 'caso Radilla"'), debe repararse desde un inicio en que en este asunto el pleno no tuvo por propósito discutir propiamente el objeto del juicio de amparo. No obstante, sí generó una comprensión distinta de los derechos que consagra la Constitución Federal, a partir de la reforma del 6 de junio de 2011. Además, caracterizó una distinta perspectiva, generada por el propio derecho constitucional positivo, acerca de cuáles son los derechos humanos (que no ya "garantías individuales", expresión que en esta resolución se abandona implícitamente) que deben tomarse en consideración al ejercer el control de constitucionalidad y -a partir de esta decisión- también el de convencionalidad ex officio en materia de derechos humanos.

A partir de esta trascendente resolución, se desprende una convicción del Tribunal Pleno -o al menos de una mayoría de sus integrantes- para interrumpir un esquema jurisdiccional previo, inmovilizado durante décadas en los aspectos que fueron finalmente resueltos. Por otro lado, en ella se sentaron las bases para orientar un sendero distinto en el quehacer de la justicia constitucional mexicana, en cuanto a la aplicación de normas de derechos humanos se refiere ${ }^{16}$.

Cabe advertir que los criterios emanados de "varios 912/2010" no consiguieron la adhesión unánime de los ministros integrantes del pleno, aunque son dos las notables excepciones: el relativo a la obligatoriedad de las sentencias condenatorias de la Corte Interamericana, y la restricción del fuero miliar. Sin embargo, ninguno de esos criterios generó "jurisprudencia", esto es, criterios jurídicamente vinculantes, pues el procedimiento del que emergieron (un expediente "varios") ${ }^{17}$ no revistió la aptitud jurídico-procesal para producir esos efectos. Dichos criterios integraron "tesis aisladas", es decir, tesis orientadoras para todos los tribunales y los operadores jurídicos del país,

16 La resolución fue incluso publicada en el Diario Oficial de la Federación el 4 de octubre de 2011, lo que resulta más que simbólicamente significativo no solo porque en esa fecha la Corte determinó la apertura de la décima época del Semanario Judicial de la Federación. Recuérdese que, además, en ese mismo día entraron en vigor las reformas constitucionales en materia de juicio de amparo, de acuerdo con lo dispuesto por el artículo primero transitorio del multimencionado Decreto del 6 de junio de 2011.

17 El pleno fundó su competencia para resolver este caso en la atribución genérica e indefinida que le concede el artículo 10-XI de la Ley Orgánica del Poder Judicial de la Federación, que dispone: "La Suprema Corte de Justicia conocerá funcionando en Pleno: [...] De cualquier otro asunto de la competencia de la Suprema Corte de Justicia, cuyo conocimiento no corresponda a las Salas". Y agregó que el pleno era competente para resolver "toda vez que el propio Pleno determinó, el siete de septiembre de dos mil diez (en el diverso expediente varios 489/2010), que debe hacer una declaración acerca de la posible participación del Poder Judicial de la Federación en la ejecución de la sentencia dictada por la Corte Interamericana de Derechos Humanos en el caso Radilla Pacheco contra los Estados Unidos Mexicanos, ante la duda que genera la inexistencia de normas legales expresas que regulen su ejecución, y a la importancia que dicho caso reviste para el orden jurídico nacional" (párr. 10, considerando primero, de la resolución al expediente varios 912/2010). 
lo cual, por cierto, generó no pocas incertidumbres a la hora de enfrentar su aplicación en la práctica judicial.

No es este el lugar para analizar los peculiares antecedentes que dieron lugar a la resolución del expediente "varios 912/2010"18. Pero es obligado hacer notar que si bien se resolvió en definitiva por la Corte unos días después de haber cobrado vigencia el nuevo marco constitucional (el 14 de julio de 2011), en realidad sus extremos fueron consecuencia de las consideraciones que había hecho la Corte Interamericana de Derechos Humanos en su sentencia al caso "Rosendo Radilla Pacheco vs. Estados Unidos Mexicanos", dictada el 23 de noviembre de 2009. En esta sentencia internacional, el Estado mexicano fue condenado por dicha Corte a diversas actuaciones, como consecuencia del acreditamiento de violaciones, entre otros, a los derechos a la libertad personal, a la integridad personal, al reconocimiento de la personalidad jurídica y a la vida, consagrados en los artículos 7.1, 5.1, 5.2, 3 y 4.1 de la Convención Americana sobre Derechos Humanos, en perjuicio de la víctima.

De las varias determinaciones importantes de la Suprema Corte en el expediente varios 912/2010, solamente destacaré las que poseen una inevitable relación con el objeto de protección del nuevo juicio de amparo, y que prepararon el camino jurisprudencial que vino después, sobre todo, para lo determinado en las decisiones en las que desembocaron las contradicciones de tesis 293/2011 y 21/2011-PL.

Prácticamente durante toda la vigencia de la Constitución federal de 1917, la Suprema Corte había mantenido una interpretación inconmovible en el sentido de que el sistema de control de constitucionalidad imperante en México era el concentrado en los tribunales de la Federación, pese a que la lectura del artículo 133 constitucional parecía sugerir otra cosa. Mediante el juicio de amparo, los juzgados y tribunales federales (jueces de distrito y tribunales colegiados de circuito) eran los órganos judiciales encargados de operar la justicia constitucional, con la proscripción de que en esa labor pudiere intervenir cualquier otro juez, de cualquier materia, fuero, o instancia, incluidos los integrantes de los poderes judiciales de los Estados.

Pues bien, en la resolución del expediente varios 912/2010, la Suprema Corte decidió modificar esa lógica concentradora del control de constitucionalidad de los actos de autoridad, incluida, destacadamente, la autoridad legislativa. En la tesis P. Lxx/2011 (9..) se determina que, en la actualidad, existen dos vertientes dentro del modelo de control de constitucionalidad en el orden jurídico mexicano, las que, además, son acordes con el modelo que

18 Al respecto, entre otros, cfr., p. ej.: José Ramón Cossío Díaz, Raúl M. Mejía Garza, y Laura Patricia Rojas Zamudio, El caso Radilla. Estudio y documentos, México, Porrúa, 2012; Eduardo Ferrer Mac-Gregor, y Fernando Silva García, Jurisdicción militar y derechos humanos. El caso Radilla ante la Corte Interamericana de Derechos Humanos, México, Porrúa/ UNAM, 2011. 
denominó de "control de convencionalidad ex officio en materia de derechos humanos", a cargo de los jueces.

En primer término, se encuentra el control concentrado en los órganos del Poder Judicial de la Federación con vías directas de control, en donde se localizan las acciones de inconstitucionalidad (el control abstracto de normas legales) y las controversias constitucionales (conflictos entre poderes y órganos públicos), ambas competencias de la Corte; y el juicio de amparo directo e indirecto, competencia de los jueces y tribunales federales y, excepcionalmente, también de la Corte ${ }^{19}$. En segundo término -aquí, el aspecto novedoso de su criterio- se encuentra el control de constitucionalidad en forma incidental que deberán operar el resto de los jueces del país, en los procesos ordinarios en los que sean competentes.

En este criterio, lo destacado a nuestros efectos es que el objeto de protección del juicio de amparo, en realidad, fue incluso ensanchado en un sentido exorbitante del propio medio específico de control de constitucionalidad por la Suprema Corte: admitió que los derechos humanos, tanto los consagrados en el orden constitucional como los del orden internacional, son tutelables, no solo mediante el juicio de amparo, sino también en los procesos ordinarios respectivos, de la competencia de todos los jueces del país. En este sentido, desde ese momento la Corte admitió el ejercicio paralelo del control difuso de actos violatorios de los derechos humanos - a cargo de todos los juecescon las competencias de amparo en manos de los tribunales de la Federación, que tendría reconocido ese mismo objeto. En este nuevo sistema, como lo sostienen FERRER MAC-GREgor y SÁnchez GIL, en caso de omisión de ejercer control difuso de actos violatorios de derechos humanos, sin embargo, no debiera tener el efecto de devolver el asunto a la autoridad ordinaria para subsanar la deficiencia, en nombre del principio de economía procesal ${ }^{20}$.

Para la Corte, se trata de un sistema concentrado en una parte y difuso en otra, lo que permite que sean los criterios derivados de las declaraciones de inconstitucionalidad o de las determinaciones de inaplicación, que advierta la propia Corte, lo que determine la interpretación constitucional que finalmente debe prevalecer en el orden jurídico nacional. Ambas vertientes de control deben ejercerse de manera independiente, lo que significa que la existencia del referido modelo general de control no requiere que todos los casos sean revisables e impugnables en ambas.

19 Para una exposición sintética sobre la intervención excepcional de la Suprema Corte en los recursos de revisión de los juicios de amparo, permítaseme la remisión a Herrera García, Alfonso, "Suprema Corte de Justicia de la Nación" en Diccionario Histórico Judicial de México. Ideas e Instituciones, t. III, México, Suprema Corte de Justicia de la Nación, 2010, pp. 1584-1599.

20 Cfr. Eduardo Ferrer Mac-Gregor, y Rubén SÁnchez Gil, El nuevo juicio de amparo. Guía de la reforma constitucional y la nueva Ley de Amparo, México, Porrúa/UnAm/IMDPC, 2013, p. 31 . 
Además, en esta redefinición del modelo general de control de constitucionalidad se toma también en cuenta la tarea del resto de autoridades públicas del país. En el ámbito de sus competencias, estas tienen también la obligación de aplicar las normas jurídicas bajo una lógica de interpretación más favorable a la persona (pro persona), para obtener una protección más amplia de sus derechos humanos. No obstante, a diferencia de los jueces, las autoridades no-judiciales no cuentan con facultades para inaplicar o declarar la incompatibilidad de dichas normas con la Constitución General de la República' ${ }^{21}$.

Esta reconfiguración del modelo general de control de constitucionalidad trajo como consecuencia que en un posterior asunto (la llamada "Solicitud de modificación de jurisprudencia 22/2011") 22, la Corte declarara que quedaran sin efectos jurídicos las tesis jurisprudenciales P./J. 73/99 y P./J. 74/99, cuyos elocuentes rubros eran los siguientes: "CONTROL JUDICIAL DE LA CONSTITUCIÓN. Es atribución EXClusiva del Poder Judicial de la Federación”, y “CONTROL DIFUSO DE LA CONSTITUCIONALIDAD DE NORMAS GENERALES. NO LO AUTORIZA EL ARTículo 133 DE LA CONSTITUCIÓN"23. Se aclaró que esta conclusión se derivaba del marco constitucional generado con motivo de la entrada en vigor de la reforma en materia de derechos humanos del 10 de junio de 2011.

Además de las referidas vertientes concentrada y difusa del control de constitucionalidad, la Suprema Corte introdujo en ese modelo la doctrina que en sede de jurisdicción interamericana se ha denominado "control de convencionalidad" ex officio en materia de derechos humanos ${ }^{24}$. Esta decisión se apoyó en la nueva redacción del artículo 1. ${ }^{\circ}$, párrafo segundo, de la Constitución, que, como se puso de relieve con anterioridad, establece que todas las autoridades del país, en el ámbito de sus competencias, están obligadas a velar no solo por los derechos humanos contenidos en la Constitución federal, sino también por aquellos contenidos en los tratados internacionales celebrados por el Estado mexicano, debiéndose adoptar la interpretación más favorable al derecho humano de que se trate.

Los mandatos interpretativos contenidos en el artículo $1 .^{\circ}$ constitucional, sostuvo la Corte, deben cohonestarse con el artículo 133 de la propia Cons-

21 El ministro encargado del engrose de la resolución al expediente varios 912/2010 fue José Ramón Cossío Díaz. En cuanto al criterio de que se trata, hubo mayoría de 7 votos; votaron en contra los ministros Aguirre Anguiano, Pardo Rebolledo y Aguilar Morales.

22 Ponente: Olga SÁnchez Cordero. Mayoría de 9 votos; votaron en contra y por la modificación de las tesis jurisprudenciales (no por la declaratoria "sin efectos"), los ministros Valls Hernández y Sánchez Cordero.

23 Las tesis P./J. 73/99 y P./J. 74/99 fueron publicadas en el Semanario Judicial de la Federación y su Gaceta, novena época, t. x, agosto de 1999, pp. 18 y 5, respectivamente.

24 Cfr. Miguel Carbonell, "Introducción general al control de convencionalidad", en El constitucionalismo contemporáneo. Homenaje a Jorge Carpizo, LuIs R. GonzÁlez Pérez y Diego Valadés, coords., México, unam-IIJ, 2013, pp. 67-95. 
titución, para definir el marco dentro del cual debe realizarse el control de convencionalidad ex officio en materia de derechos humanos a cargo de los jueces, y que se encuentra inserto en el modelo nacional de control de constitucionalidad. Mediante una interpretación sistemática del texto de nuevo cuño, se determinó que, en consonancia con la última parte del artículo 133, en los casos litigiosos de su conocimiento, los jueces están obligados a preferir los derechos humanos contenidos en la Constitución y en los tratados internacionales, a pesar de las disposiciones en contrario que se encuentren en cualquier norma jurídica inferior.

Se precisó además que si bien los jueces no tienen competencia para emitir una declaración general sobre la invalidez (expulsar del orden jurídico), las normas que consideren contrarias a los derechos humanos (los tribunales de la Federación pueden emitir declaratorias de inaplicación a casos concretos en juicios de amparo, y la Suprema Corte declaratorias de invalidez general en los procesos de acciones de inconstitucionalidad y controversias constitucionales), todos los jueces están obligados a dejar de aplicar las normas inferiores, en caso de conflicto normativo con las contenidas en la Constitución y en tratados internacionales ${ }^{25}$.

En la línea de estos criterios, la resolución al varios 912/2010 generó, por primera vez en la historia judicial de México, el reconocimiento de vinculatoriedad de las sentencias emitidas por un tribunal internacional -la Corte Interamericana de Derechos Humanos-, no solo en lo que respecta a sus puntos resolutivos, sino también a la fundamentación jurídica en que tales sentencias se apoyan -"en sus términos"-, tanto para la propia Corte mexicana como para todos los jueces y demás autoridades del país, siempre que el Estado mexicano haya sido parte en el litigio resuelto por la sentencia. Esta determinación también cobra un impacto inmediato en el objeto del juicio de amparo, tomando en cuenta que las consideraciones de las sentencias condenatorias de la Corte Interamericana resultan clave para entender aquello que ahora resulta protegible contra las violaciones a derechos humanos consagrados en la Convención Americana.

Las razones torales en que se fundó esa decisión consideraron que si el Estado mexicano aceptó la jurisdicción de la Corte Interamericana de Derechos Humanos, cuando este ha sido parte en una controversia o litigio ante esa jurisdicción, la sentencia que se dicta en esa sede constituye cosa juzgada. Así, corresponde exclusivamente a ese órgano internacional, en el caso sometido a su jurisdicción, evaluar todas y cada una de las excepciones formuladas por el Estado mexicano, tanto si están relacionadas con la extensión de la competencia de la misma Corte como si lo están con las reservas

25 Tesis aislada P. LXVII/2011(9. $\left.{ }^{a}\right)$. Mayoría de 7 votos; votaron en contra los ministros Aguirre Anguiano, Pardo Rebolledo y Aguilar Morales. 
y salvedades formuladas por el mismo Estado. Por ese motivo, la Suprema Corte mexicana debe declararse incompetente para analizar, revisar, calificar o decidir acerca de la corrección o supuesta incorrección de una sentencia dictada por la Corte Interamericana, o si esta supuestamente excede las normas que rigen su materia y proceso. Esto significa que la Corte mexicana es un tribunal al que solo corresponde "acatar y reconocer la totalidad de la sentencia en sus términos" 26 , con lo que ello signifique para la redefinición de su estatus institucional.

Por otro lado, en el expediente varios 912/2010 se concluyó que otra era la situación cuando se trataba de casos ante la Corte Interamericana en los que el Estado mexicano no hubiere intervenido como parte en la controversia. En este supuesto -se determinó en esa oportunidad-, los criterios de dicha Corte internacional resultaban solamente orientadores para los jueces mexicanos, "siempre que sean más favorables a la persona en términos del artículo $1 .{ }^{\circ}$ de la Constitución federal". Más adelante, como veremos, este criterio fue superado por la decisión a la contradicción de tesis 293/2011, en el sentido de admitir la obligatoriedad de toda la jurisprudencia interamericana.

En esa tesitura, la Corte mexicana precisó que los jueces, al resolver los casos concretos que se presenten a su consideración, deben observar los derechos humanos establecidos en la Constitución mexicana y en los tratados internacionales de los que el Estado mexicano sea parte, así como los criterios emitidos por el Poder Judicial de la Federación al interpretarlos, y acudir luego a los criterios interpretativos de la Corte Interamericana para evaluar si existe alguno que resulte más favorable y procure un beneficio más amplio del derecho "que se pretende proteger". Ello no prejuzga la posibilidad -advirtió la Corte- de que los criterios internos cumplan de mejor manera lo establecido por la Constitución en términos de su artículo $1 .^{\circ}$ (cláusula pro persona), lo cual tendrá que valorarse caso a caso, "a fin de garantizar siempre la mayor protección de los derechos humanos" 27 . La incidencia de esta determinación en el análisis de violaciones a los derechos, a través del juicio de amparo, es manifiesta.

26 Tesis aislada P. LXv/2011 (9. a). Unanimidad de 11 votos, en relación con la obligatoriedad de estas sentencias, con salvedades de los ministros Aguirre Anguiano, Luna Ramos, Franco González Salas y Aguilar Morales. Mayoría de 8 votos en cuanto a la imposibilidad de revisar si se configura alguna de las excepciones del Estado mexicano al reconocimiento de la jurisdicción contenciosa de la Corte Interamericana, o alguna de las reservas o declaraciones interpretativas formuladas por el Estado; votaron en contra: ministros Aguirre Anguiano, Luna Ramos y Aguilar Morales.

27 Entre las derivadas de la "recepción del caso Radilla", esta fue la decisión más dividida entre los integrantes del pleno, pues únicamente alcanzó el consenso de 6 ministros, contra 5. Cfr. tesis aislada P. LXvi/2011 (9. $\left.{ }^{a}\right)$. Votaron en contra los ministros Cossío Díaz, Zaldívar Lelo de Larrea, Valls Hernández, Sánchez Cordero y Silva Meza. 
Pero no terminan ahí los criterios de calado generados con la "Recepción del "caso Radilla". Con el esfuerzo de delinear con mayor precisión la forma en que debe operar el que puede llamarse "nuevo modelo integral del control difuso de regularidad", la Corte configuró el que denominó "parámetro de control de convencionalidad ex officio en materia de derechos humanos". El propósito de la Corte es pedagógico también en este punto. Trata de compatibilizar el modelo general de control de constitucionalidad interno con el control, también interno, de convencionalidad de las normas de derechos humanos ${ }^{28}$.

Así, sostuvo que el parámetro de análisis que deben ejercer todos los jueces del país -incluidos los federales a través de su jurisdicción de amparo, se entiende- se integra por los elementos normativos siguientes: a) los derechos humanos contenidos en la Constitución federal (con fundamento en los artículos $1 .^{\circ}$ y 133), así como la jurisprudencia emitida por los tribunales del Poder Judicial de la Federación (Suprema Corte y Tribunales Colegiados de Circuito); b) los derechos humanos contenidos en tratados internacionales en los que el Estado mexicano sea parte; c) los criterios vinculantes de la Corte Interamericana de Derechos Humanos derivados de las sentencias en las que el Estado mexicano haya sido parte, y d) los criterios orientadores de la jurisprudencia y precedentes de dicha Corte cuando el Estado mexicano no haya sido parte ${ }^{29}$. De nueva cuenta, el objeto del juicio de amparo tendría en estas directrices unas orientaciones más precisas acerca del sentido de su extensión.

Ahora bien, la Corte también introduce una especie de recetario metodológico para hacer frente a ese complejo sistema de control de regularidad, en lo que denominó como "pasos a seguir" para su operatividad, con especial atención al principio de presunción de constitucionalidad de las leyes. Estableció que la posibilidad de inaplicar leyes por los jueces del país no supone el desconocimiento de dicho principio, sino que estos deben partir de esa presunción y realizar de esta manera un contraste constitucional de las leyes, previo a su aplicación a los casos concretos.

Así, al ejercer el control de convencionalidad ex officio en materia de derechos humanos, la Corte estableció que deben realizarse los siguientes "pasos": a) "Interpretación conforme en sentido amplio", que significa que los jueces del país "y todas las demás autoridades del Estado mexicano" deben interpretar el orden jurídico a la luz y conforme a los derechos humanos

28 Cfr. Sergio García Ramírez, "El control judicial interno de convencionalidad", en AA.vv., Control difuso de convencionalidad. Diálogo entre la Corte Interamericana de Derechos Humanos y los jueces nacionales, E. FERRER MAC-GREGOR, coord., Querétaro, Fundación Universitaria de Derecho, Administración y Política, 2012, pp. 211-243.

29 Tesis aislada P. LXVIII/2011 (9. $\left.{ }^{a}\right)$. Mayoría de 7 votos; votaron en contra los ministros Aguirre Anguiano, Pardo Rebolledo y Aguilar Morales. 
reconocidos en la Constitución y en los tratados internacionales en los que el Estado mexicano sea parte, favoreciendo en todo tiempo a las personas con la protección más amplia; b) "Interpretación conforme en sentido estricto", que significa que cuando haya varias interpretaciones jurídicamente válidas, partiendo de la presunción de constitucionalidad de las leyes, los jueces deben preferir aquella que haga a la ley acorde a los derechos humanos reconocidos en la Constitución y en los tratados internacionales en los que el Estado mexicano sea parte ${ }^{30}$, "para evitar incidir o vulnerar el contenido esencial de estos derechos"; y,c) "Inaplicación de la ley" cuando no sea posible efectuar una interpretación conforme de la norma analizada, frente a la Constitución ${ }^{31}$.

\section{La contradicción de tesis 293/2011: una construcción implícita del objeto de protección}

La contradicción de tesis 293/2011 produjo los criterios más trascendentes, hasta la fecha, para la definición de los alcances de la reforma constitucional en materia de derechos humanos, desde el expediente varios 912/2010. Una de las razones que justificaron la necesidad de estudiar el fondo de esta contradicción consistió en que la resolución del expediente "varios" no zanjó el tema de la jerarquía de los tratados en materia de derechos humanos. Por consiguiente, pese a que tampoco se trató de dotar de específico contenido interpretativo al artículo 103 constitucional, lo cierto es que la resolución de esta contradicción debe tenerse también como definitoria del objeto de protección del nuevo juicio de amparo, al haberse generado un criterio angular del orden constitucional. Además, la importancia de este asunto se cifra en que sí generó jurisprudencia y que se decidió en un momento en el que ya se encontraban en vigor tanto la reforma constitucional del 6 de junio de 2011 como la nueva Ley de Amparo (vigente, como se ha dicho, a partir del 3 de abril de 2013, de conformidad con el artículo único transitorio del decreto respectivo).

En esta contradicción de tesis, la Corte definió dos temas fundamentales. En primer lugar, la relación que deben mantener la Constitución y los tratados internacionales en materia de derechos humanos. Ello repercutió, entre otras tantas cosas, en la configuración del parámetro de control de regularidad de todo acto de autoridad - pública o privada- lo cual, en lo que aquí interesa, repercute inmediatamente en la dimensión de los alcances del artículo 103

30 Cfr. José Luis CaBAlLERo OCHOA, "La cláusula de interpretación conforme y el principio pro persona (Artículo 1. ${ }^{\circ}$, segundo párrafo, de la Constitución)", AA.VV ., La reforma constitucional de derechos humanos. Un nuevo paradigma, Miguel Carbonell y Pedro Salazar, coords., México, UNAM/IIJ, 2011, pp. 103-133.

31 Tesis aislada P. LXIX/2011 (9. $\left.{ }^{a}\right)$. Mayoría de 7 votos; votaron en contra: ministros Aguirre Anguiano, Pardo Rebolledo y Aguilar Morales. 
constitucional, dada su ilación lógica e ineluctable con la reforma constitucional de los derechos humanos. En segundo lugar, la Corte reconsideró el grado de obligatoriedad de las sentencias de la Corte Interamericana de Derechos Humanos en las que el Estado mexicano no figuró como parte, en el orden jurídico nacional.

La conclusión a la que se llegó fue que los derechos humanos de fuente internacional tienen rango constitucional pero que, en caso de que estos se enfrenten a una restricción expresa de la Constitución, debe estarse a lo que la misma señale ${ }^{32}$. Además, se determinó que toda la jurisprudencia de la Corte Interamericana de Derechos Humanos, incluida aquella emanada de casos en los cuales el Estado mexicano no fue parte, es obligatoria en el orden jurídico mexicano, siempre que resulte más favorable para las personas ${ }^{33}$.

En consecuencia, el Tribunal Pleno, al haber admitido el mismo nivel normativo de los derechos reconocidos por la Constitución Federal con el de los derechos humanos establecidos en los tratados internacionales suscritos por el Estado mexicano, implícitamente dotó de contenido literal al artículo 103, fracción I, de la propia Constitución a los efectos de la tutela jurisdiccional por los tribunales de la Federación de todos esos derechos. En ese sentido, se confirma el ensanchamiento del objeto de protección del juicio de amparo, que es ahora un juicio para la tutela directa de los derechos humanos de fuente internacional. Y lo es tomando en cuenta no solo su contenido normativo, sino el jurisprudencial que le sea dotado por la Corte Interamericana de los Derechos Humanos en sus sentencias.

\section{La contradicción de tesis 21/2011-PL: la reconfiguración del amparo directo en revisión ante la Suprema Corte}

Inmediatamente después de resolver la contradicción de tesis 293/2011, en las sesiones del 5 y 9 de septiembre de 2013, el Tribunal Pleno discutió otro tema de gran relevancia al resolver la contradicción de tesis 21/2011-PL. Aunque este asunto siguió la estela argumentativa de la contradicción previa, su problemática presentó particularidades propias, de notable complejidad técnica y con un impacto también inmediato en la práctica del juicio de amparo. En este caso, se discutió acerca de la repercusión de la nueva condición jurídica de los derechos humanos de fuente internacional en el ejercicio de una de las principales competencias de la Suprema Corte: el amparo directo en revisión.

32 Determinación que se alcanzó por mayoría de 10 votos, con el voto en contra del ministro Cossío Díaz.

33 Esta decisión se adoptó por mayoría de 6 votos, con los votos en contra de la ministra Luna Ramos y los ministros Franco González Salas, Pardo Rebolledo, Aguilar Morales y Pérez Dayán. Al momento en que se escriben estas líneas, el asunto se encuentra pendiente de "engrose". 
En concreto, el punto a resolver en esta contradicción -en la que fueron las dos Salas de la propia Corte los órganos jurisdiccionales en discrepancia- era el siguiente: si el problema de compatibilidad entre una ley y un tratado internacional es una "cuestión de constitucionalidad" o una "cuestión de legalidad" a efecto de decidir la procedencia de un amparo directo en revisión ante la Corte.

La Primera Sala sustentó la tesis de que esa problemática redundaba en una cuestión de constitucionalidad y que, por tanto, la revisión es procedente. Por el contrario, la Segunda Sala estableció que ese problema era una cuestión de legalidad y que, de este modo, no reunía el mérito suficiente para admitir la revisión. Desde que emitieron sus respectivos criterios, ambas Salas los venían aplicando en los asuntos materia de sus respectivas competencias, con lo cual las líneas jurisprudenciales que fueron desarrollándose marcaron una riesgosa incertidumbre para los justiciables que decidieron proponer ante la Corte la revisión de sentencias de amparo directo, emitidas por Tribunales Colegiados de Circuito.

Como se sabe, desde la perspectiva procesal, la procedencia del recurso de revisión es excepcional, como reiteradamente afirma la Corte en las resoluciones de desechamiento de estos recursos. Así, excepcional es también el acceso de los justiciables a la jurisdicción del máximo tribunal del país. Para la Primera Sala, el problema jurídico planteado en la contradicción abre la puerta de la Corte. Para la Segunda Sala, no. Así, la conclusión de este asunto se traducía en la definición de un estándar elemental a partir del cual la Corte, de ahora en adelante, debe analizar las pretensiones jurídicas que soliciten la revisión de sentencias de los Tribunales Colegiados, en materia de derechos humanos.

Pues bien, el Tribunal Pleno, con base en lo decidido en la contradicción de tesis 293/2011, resolvió que un problema de compatibilidad entre un tratado internacional y una ley es una "cuestión de constitucionalidad" si está en juego determinar el alcance de un derecho humano. Cualquier discrepancia normativa que se ventile en este sentido en un juicio de amparo, debe entenderse como una "cuestión constitucional". Esta decisión precisó una acotación: si ese problema de fuentes no involucra la aplicación de un derecho humano, entonces debe considerarse que el problema permanece en la condición de "cuestión de legalidad", terreno en el cual las sentencias de los Tribunales Colegiados son definitivas e inatacables.

Como se ha reiterado, el artículo 103 constitucional, fracción I, expresamente establece que el amparo procede contra violaciones a "los derechos humanos reconocidos y las garantías otorgadas para su protección por (la) Constitución, así como por los tratados internacionales de los que el Estado mexicano sea parte". Sin embargo, en cuanto al recurso de revisión, el artículo 107 sigue expresando que la materia del recurso "se limitará a la decisión 
de las cuestiones propiamente constitucionales, sin poder comprender otras" (fracción IX).

En el asunto que se comenta, la Suprema Corte interpretó que ahí donde el artículo 107 expresa que en la revisión deben tratarse cuestiones "propiamente constitucionales", debe leerse en el sentido de que abarca las "cuestiones propiamente convencionales de derechos humanos". Es decir, ahora este precepto debe leerse en el sentido de que procede la revisión contra sentencias de amparo que resuelvan sobre la convencionalidad de normas generales, o establezcan la interpretación directa del precepto de un tratado de derechos humanos, u omitan hacerlo, habiéndose planteado en la demanda de amparo. A ello debe añadirse que la cuestión planteada debe revestir un criterio de importancia y trascendencia (p. ej., si no existe jurisprudencia de la Corte aplicable al tema de que se trata) ${ }^{34}$. Así, se formaliza la interpretación del pleno en el sentido de que, para la Corte, no es indiferente lo resuelto por los Tribunales Colegiados respecto a la interpretación de derechos humanos de fuente internacional en un juicio de amparo directo.

Por lo demás, debe recordarse que ha sido la propia nueva Ley de Amparo la que se encargó de reconocer, en su artículo 81, fracción II, la procedencia de la revisión en amparo directo contra las sentencias que establezcan la interpretación directa de un precepto constitucional o de los derechos humanos establecidos en los tratados internacionales de los que el Estado mexicano sea parte, en los términos que a continuación se transcriben:

Art. 81.- Procede el recurso de revisión:

$[\ldots]$

II. En amparo directo, en contra de las sentencias que resuelvan sobre la constitucionalidad de normas generales que establezcan la interpretación directa de un precepto de la Constitución Política de los Estados Unidos Mexicanos o de los derechos humanos establecidos en los tratados internacionales de los que el Estado Mexicano sea parte, $u$ omitan decidir sobre tales cuestiones cuando hubieren sido planteadas, siempre que fijen un criterio de importancia y trascendencia, según lo disponga la Suprema Corte de Justicia de la Nación, en cumplimiento de acuerdos generales del pleno.

La materia del recurso se limitará a la decisión de las cuestiones propiamente constitucionales, sin poder comprender otras.

34 Véase el punto primero (procedencia) del "Acuerdo número 5/1999, del veintiuno de junio de mil novecientos noventa y nueve, del Pleno de la Suprema Corte de Justicia de la Nación, que establece las bases generales para la procedencia y tramitación de los recursos de revisión en amparo directo". 
Si bien, un tanto contradictoriamente, la última parte de esta fracción insiste (como lo hace la última parte de la fracción IX del artículo 107 constitucional) en que la materia del recurso se "limitará" a las "cuestiones propiamente constitucionales", el artículo 96 de la propia Ley de Amparo vigente arroja mayores elementos de análisis sobre la precisión del sentido expansivo de esta expresión, al establecer que, cuando se trate de la revisión de sentencias de amparo directo pronunciadas por los Tribunales Colegiados de Circuito,

... la Suprema Corte de Justicia de la Nación resolverá únicamente sobre la constitucionalidad de la norma general impugnada, o sobre la interpretación directa de un precepto de la Constitución Política de los Estados Unidos Mexicanos o de los derechos humanos establecidos en los tratados internacionales de los que el Estado Mexicano sea parte.

Lo transcrito no podría significar otra cosa que, en la línea de lo decidido en la contradicción de tesis 21/2011-PL, la literal "cuestión propiamente constitucional" abriga una implícita vertiente de "cuestión de convencionalidad en materia de derechos humanos", como característica neurálgica del nuevo sistema del amparo mexicano.

Para finalizar, no está de más mencionar que el Acuerdo General 5/2013, del pleno de la Suprema Corte ${ }^{35}$, aprobado en mayo de 2013, establece una regla análoga a la explicada, ahora aplicable al amparo indirecto, cuando en su punto cuarto, fracción I, inciso B), dejó establecido lo siguiente:

Cuarto. De los asuntos de la competencia originaria de la Suprema Corte de Justicia de la Nación, con las salvedades especificadas en los Puntos Segundo y Tercero de este Acuerdo General, corresponderá resolver a los Tribunales Colegiados de Circuito:

Los recursos de revisión en contra de sentencias pronunciadas por los Jueces de Distrito o los Tribunales Unitarios de Circuito, cuando:

\section{$[\ldots]$}

B) En la demanda se hubiere impugnado una ley local, un reglamento federal o local, o cualquier disposición de observancia general, salvo aquéllos en los que el análisis de constitucionalidad respectivo implique fijar el alcance de un derecho humano previsto en tratados internacionales de los que el Estado Mexicano

35 Su denominación oficial es: “Acuerdo General número 5/2013, de trece de mayo de dos mil trece, del Tribunal Pleno de la Suprema Corte de Justicia de la Nación, relativo a la determinación de los asuntos que el Pleno conservará para su resolución, y el envío de los de su competencia originaria a las Salas y a los Tribunales Colegiados de Circuito", publicado en el Diario Oficial de la Federación el 21 de mayo de 2013. 
sea parte, respecto del cual no exista jurisprudencia del Pleno o de las Salas de este Alto Tribunal, sin menoscabo de que la Sala en la que se radique el recurso respectivo determine que su resolución corresponde a un Tribunal Colegiado de Circuito... (cursivas nuestras).

\section{PROSPECTOS Y RETOS}

A partir de los criterios descritos en el apartado anterior, provenientes de asuntos resueltos por el pleno de la Suprema Corte -que podrían merecer la categoría de lo que en la doctrina se conoce como leading cases-, y de las renovadas premisas construidas a partir de ellos, cabe preguntarse acerca de la prospectiva y los retos que representan las reformas constitucional y legal del objeto de protección que, bajo su nuevo esquema, caracteriza al juicio de amparo.

Ha transcurrido poco tiempo desde que entró en vigor la nueva Ley de Amparo, y, consecuentemente, muchos son los interrogantes que se desprenden en ese sentido. Por cuestiones de espacio, y de debida prudencia, solamente destacaré cinco retos que la temática que se ha tratado presenta para los operadores y estudiosos del derecho de amparo mexicano.

En primer lugar, se tiene que, con el criterio adoptado por la Suprema Corte en la referida contradicción de tesis 293/2011, estamos ante la presencia de un catálogo de derechos humanos en la Constitución dentro del cual deben considerarse insertos los existentes en tratados internacionales. Así, el objeto del amparo se dirige hacia un universo difuso e indeterminado de ese catálogo. El problema de esta representación es que el grado de ensanchamiento de ese catálogo -que equivale al grado de amplitud del parámetro de control de regularidad- resulta directamente proporcional al grado de incerteza de las normas que lo integran. En estas condiciones, el ejercicio de fijación de ese parámetro es, a priori, intencionalmente infinito. Además, esa falta de confines normativos equivale a una ausencia de precisión ex ante de los deberes exigibles a los poderes públicos. En este sentido, un reto de la jurisdicción de amparo ante los tribunales de la Federación es no solo la construcción, sino también una sistemática acotación normativa, de los derechos humanos tutelables en el actual régimen de amparo.

En segundo lugar, se encuentra el problema cuya discusión inagotada finalmente desencadenó el criterio jurisprudencial surgido de la contradicción de tesis 293/2011, que es el relativo al modo de operar las restricciones expresas de los derechos humanos reconocidos en la Constitución, frente a su eventualmente dispar configuración normativa en el orden internacional. Es bien sabido que prevalecen en el texto constitucional mexicano un cúmulo de restricciones explícitas a ciertos derechos que no son necesariamente armónicas con los estándares internacionales de esos mismos derechos, ya sea a nivel normativo o incluso a nivel jurisprudencial. La aplicación concreta de 
esta confluencia de órdenes normativos en estos casos planteará serios retos a los tribunales de la Federación, tomándose en cuenta que la determinación de la Corte ha sido clara en el sentido de que no puede llegarse al extremo de inaplicar esas restricciones, pese al igual nivel jerárquico de los derechos humanos de fuente internacional.

En tercer lugar, puede enunciarse el reto que plantea el tratamiento judicial de disposiciones contenedoras de derechos que, perteneciendo formalmente a tratados internacionales, éstos no tengan por objeto la configuración de derechos humanos, sino otras materias más o menos diversas. No está claro si podrían resultar amparables derechos de una fuente "especial" simplemente por perseguir el tratado que los recoge propósitos de tipo económico, fiscal, o de otra índole (piénsese en el ejemplo, ya clásico, de la Convención de Viena sobre Relaciones Consulares).

En cuarto lugar, se encuentra el dilema de si resultaría admisible la tutela autónoma (es decir, sin conexión necesaria con algún derecho constitucional), de un derecho consagrado, por ejemplo, en la Convención Americana sobre Derechos Humanos, que se plantee en el capítulo de derechos violados de una demanda de amparo. Este supuesto podría resultar el conducente en supuestos de derechos consagrados en la Convención que no encuentren un asidero específico en la Constitución mexicana (piénsese, p. ej., en el derecho a la personalidad jurídica, establecido en su artículo 3. ${ }^{\circ}$; o el derecho al nombre, reconocido en su artículo 18$)^{36}$.

En quinto lugar, pueden simplemente enunciarse algunos otros problemas que tienen como común denominador su inédita irrupción en el sistema nacional del amparo desde el derecho internacional, como son el aún indefinido alcance y consecuente operatividad de instrumentos internacionales que no revisten formalmente la calidad de tratados (piénsese en la Declaración Universal de los Derechos Humanos, o la Declaración Americana de los Derechos y Deberes del Hombre, p. ej.); o el diverso problema que plantea el valor jurídico también incierto de acuerdos o determinaciones distintas de las sentencias, como pueden ser las opiniones consultivas de la Corte Interamericana de los Derechos Humanos, haya o no participado como parte, en el respectivo procedimiento, el Estado mexicano.

Se trata solamente de una enunciación básica de un cúmulo exponencial de problemáticas y retos que plantea no solo la construcción jurisprudencial del objeto de protección del nuevo juicio de amparo, sino del entero sistema de derechos humanos en el orden jurídico mexicano. Será en un futuro, probablemente no tan distante, cuando se continúen edificando los cimientos

36 Cfr. Édgar Corzo Sosa, "Estudio introductorio", Nueva Ley de Amparo 2013, México, Tirant lo Blanch, 2013, p. 16. En la doctrina, autores como Eduardo Ferrer MaC-Gregor y RubÉN SÁnchez GIL se han pronunciado positivamente en ese sentido. Cfr. su El nuevo juicio de amparo, cit., p. 5. 
asequibles a la profunda transformación jurídica del modelo de amparo y de los derechos por él tutelados, en la cual se encuentra inmerso el Estado mexicano en la hora presente.

\section{BIBLIOGRAFÍA}

AA.vv., Control difuso de convencionalidad. Diálogo entre la Corte Interamericana de Derechos Humanos y los jueces nacionales, E. Ferrer MAC-Gregor, coord., Querétaro, Fundación Universitaria de Derecho, Administración y Política, 2012.

AA.vv., La reforma constitucional de derechos humanos. Un nuevo paradigma, Miguel Carbonell y Pedro Salazar, coords., México, unam/inj, 2011.

Burgoa O., Ignacio, El juicio de amparo, 43. a ed., México, Porrúa, 2009.

Caballero Ochoa, José Luis, "La cláusula de interpretación conforme y el principio pro persona (Artículo 1. ${ }^{\circ}$, segundo párrafo, de la Constitución)", en AA.vv., La reforma constitucional de derechos humanos. Un nuevo paradigma, Miguel Carbonell y Pedro Salazar, coords., México, unam/IIJ, 2011.

Carbonell, Miguel, "Introducción general al control de convencionalidad", en El constitucionalismo contemporáneo. Homenaje a Jorge Carpizo, Luis R. GonzÁlez Pérez y Diego Valadés, coords., México, unam-IIJ, 2013.

CArpizo, Jorge, "Los derechos humanos: Una propuesta de clasificación de los derechos civiles y políticos", Revista de la Facultad de Derecho de México, t. LXI, n. ${ }^{\circ}$ 256, julio-diciembre, 2011.

Corzo Sosa, Édgar, "Estudio introductorio", Nueva Ley de Amparo 2013, México, Tirant lo Blanch, 2013.

Cossío Díaz, José Ramón, “Análisis de la propuesta de una nueva Ley de Amparo”, en íd., Bosquejos constitucionales, México, Porrúa, 2004.

Cossío Díaz, José Ramón; Mejía Garza, Raúl M. y Rojas Zamudio, Laura Patricia, el caso Radilla. Estudio y documentos, México, Porrúa, 2012.

Ferrer Mac-Gregor, Eduardo y Sánchez Gil, Rubén, El nuevo juicio de amparo. Guía de la reforma constitucional y la nueva Ley de Amparo, México, Porrúa/unam/ImDPC, 2013.

Ferrer Mac-Gregor, Eduardo y Silva García, Fernando, Jurisdicción militar y derechos humanos. El caso Radilla ante la Corte Interamericana de Derechos Humanos, México, Porrúa/unam, 2011.

Fix-Zamudio, Héctor, Ensayos sobre el derecho de amparo, 3. a ed., México, Porrúa-unam, 2003.

García Ramírez, Sergio, "El control judicial interno de convencionalidad", en aA.vv., Control difuso de convencionalidad. Diálogo entre la Corte Interamericana de Derechos Humanos y los jueces nacionales, E. Ferrer MAC-Gregor, coord., Querétaro, Fundación Universitaria de Derecho, Administración y Política, 2012. 
García Ramírez, Sergio y Morales Sánchez, Julieta, La reforma constitucional sobre derechos humanos (2009-2011), 2. . ed., México, Porrúa/unam, 2012.

Herrera García, Alfonso, "Suprema Corte de Justicia de la Nación", en Diccionario Histórico Judicial de México. Ideas e Instituciones, t. III, México, Suprema Corte de Justicia de la Nación, 2010.

Zaldívar Lelo de Larrea, Arturo, Hacia una nueva Ley de Amparo, México, unam-IIJ, 2002. 